\title{
Regression model accuracy comparison on mangrove canopy density mapping
}

\author{
Deha Agus Umarhadi* and Akbar Muammar Syarif \\ Remote Sensing Laboratory, Faculty of Geography, Universitas Gadjah Mada, \\ Yogyakarta, Indonesia \\ *e-mail: dehaumarhadi@gmail.com
}

\begin{abstract}
Mangrove canopy density condition is often considered in the coastal environment management, so that the accurate data of spatial distribution of mangrove canopy density is needed. This condition need to be studied further related to methods in the mangrove canopy density mapping. However, did not much research compare the mapping accuracy about mangrove canopy density using vegetation index and the combination of statistical regression models, especially using Sentinel-2A satellite imagery. The purpose of this study is to compare the accuracy of mangrove canopy density mapping using NDVI, MSAVI, and MSARVI with simple linear, quadratic, logarithmic, and exponential regression applied to Sentinel-2A satellite imagery. Mangrove canopy density data resulted from a field survey at Jor and Kecebing Bay, East Lombok. The result of accuracy analysis presented NDVI was the best vegetation index in mapping compared MSAVI and MSARVI with an accuracy above $80 \%$ (linear regression analysis of NDVI: $81.66 \%$, quadratic regression analysis of NDVI: $80.84 \%$, exponential regression analysis of NDVI: $80.71 \%$, logarithmic regression analysis of NDVI: $80.68 \%$ ). Mapping the mangrove canopy density through the combination of another vegetation index (MSAVI and MSARVI) with four regression models had accuracy of between 70 $\%$ to $80 \%$, except a mangrove canopy density mapping accuracy using quadratic regression between MSARVI and field data, only reached $62.78 \%$.
\end{abstract}

\section{Keywords}

canopy density, mangrove, regression model, Sentinel-2A, vegetation index

\section{Introduction}

Citation: Umarhadi, D.A., Syarif, A.M.: Regression model accuracy comparison on mangrove canopy density mapping. In: I.W. Mustika, I. Kartini. (eds.): Proceeding of the $3^{\text {rd }}$ International Conference on Science and Technology, Vol. 1, pp. 1-11. UGM Digital Press Physical Science and Engineering, Yogyakarta (2018).

Published: October, 2018
Mangrove is a population of vegetation that can live in coastal areas with the period of flooding due to tidal conditions in the tropical and subtropical region [1]. Mangrove ecosystem is located in the transition area between freshwater and saltwater areas. Mangroves consist of trees and shrubs that flourish in flooded and saline location [2]. The condition of mangrove forests becomes the one of an indicator in the quality of coastal ecosystems. Important roles of mangrove forest existence include coastal protection from tidal waves, abrasion and storms coming from the sea and providing economic benefits derived from biodiversity living in the mangrove ecosystem [3]. In addition, the existence of mangrove forests is to maintain soil fertility in coastal area due to its capability to supply organic materials [4].

Given the role of mangrove forests that are vital to the sustainability comprehensive mangrove forest management. In the management of 
the observation activities of the mangrove condition measurement becomes an indispensable activity. Along with the development of knowledge, remote sensing emerged as one of science and technology that can be utilized to observe the condition of mangrove thoroughly using remote sensing imagery.

One of the vital components of mangrove forest that can be observed through remote sensing images is canopy density. Sentinel-2A imagery becomes suitable data that can be used in observation of mangrove conditions because its spatial resolution, $10 \mathrm{~m}$, could map various mangrove features [5]. Observation of mangrove condition through remote sensing data is generally approached by vegetation index transformation.

Spectral transformation in remote sensing imagery can be used to generate a new information by sharpening and summarizing information [6]. Vegetation index included in spectral transformation that can be used in leaf-area-index (LAI), percentage of green cover, chlorophyll content, biomass, and absorbed photo-synthetically active radiation (APAR) studies [7], because it can accentuate vegetation aspects. Ray (1995) mentioned that vegetation index consists of basic vegetation index, minimizing soil disturbance, minimizing atmospheric disturbances, and other vegetation indices [6].

Modelling a land biophysical information using remote sensing data, such as canopy density that has ratio data, can be done using regression analysis. There are two types of regression models, i.e. linear and non-linear regression. Research on the use of regression models has been done by some previous researchers. Myeong reported non-linear regression was the best equation in carbon storage estimation for the NDVI data [8]. Myneni described a non-linear relationship between the NDVI vegetation index and the LAI, whereas FAPAR had a linear relationship [9]. While Heiskanen, recommended the use of linear regression model of the results of his research to make estimation of biomass and LAI. This study aims to compare the accuracy and analyze the results of canopy density modelling using simple linear, quadratic, logarithmic, and exponential regression using several vegetation indices (NDVI, MSAVI, and MSARVI).

\section{Methods}

\subsection{Study Area}

This study was carried out on 22-25 May 2016 at Jerowaru District, East Lombok Region, Nusa Tenggara Barat Province, especially at two locations of mangrove ecosystem, Kecebing and Jor Bay (Fig. 1). Jor Bay has alluvium surface sediment that came from volcanic materials, however Kecebing Bay from calcareous hill materials. Sea wave that relatively calm and the closed beach shape support the existence of mangrove forest. Unfortunately, pressures from agro-fisheries and settlements become threats to mangrove forest at the location.

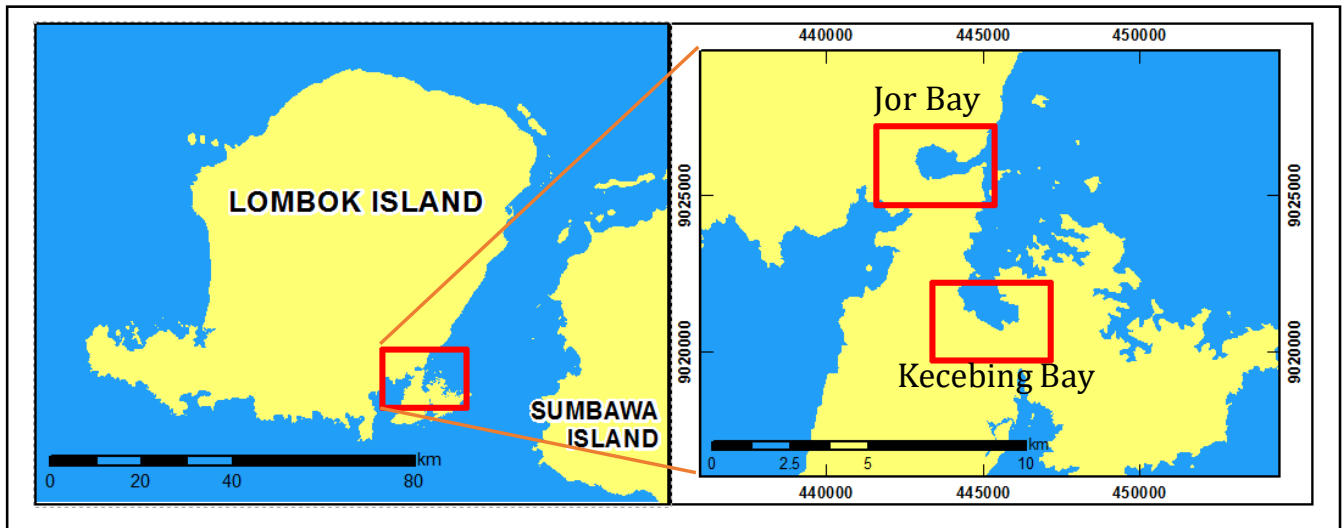

Fig. 1 Study area

\subsection{Data and Pre-processing Data}

Sentinel-2A images of acquiring date 18 May 2016 is used in this study. This satellite image is included in a multispectral image type with 13 spectral bands ( 4 bands on $10 \mathrm{~m}$ spatial resolution, 6 bands on spatial resolution of $20 \mathrm{~m}$, and 3 bands on spatial resolution of $60 \mathrm{~m}$ ). The data used in mangrove canopy density modelling were $10 \mathrm{~m}$ spatial resolution bands, which are visible and near infrared bands. 
Mangrove canopy density modelling required systematic pre-processing data from radiometric correction to atmospheric correction, and vegetation index transformations. The image downloaded at scihub.copernicus.eu has been at TOA Reflectance level. Radiometric correction was applied to correct the pixel value of the image to fit the reflection value of the object. The atmospheric correction was necessary to minimize atmospheric effect of reflected energy from the object to the sensor. Fast Line of Sight Atmospheric Analysis of Spectral Hypercubes (FLAASH) atmospheric correction method was used, which attempts to suppress the effects of water vapor, oxygen, carbon dioxide, methane, ozone, and aerosols [6]. FLAASH correction required visibility data obtained from MODIS imagery data.

Next method after FLAASH correction on Sentinel-2A image was vegetation index transformation. The transformation used 3 methods, NDVI, MSAVI, and MSARVI. Vegetation index was the approach to apply canopy density model. These three vegetation indices were selected because each index represented the basic vegetation index, suppressing the soil effect, and the combination between suppression of soil and atmospheric effects. The three indices algorithms were described on Table 1.

Table 1 Equation of vegetation index

\begin{tabular}{lll} 
Vegetation index & Algorithm & \\
\hline NDVI & $(\rho$ NIR $-\rho$ Red $) /(\rho N I R+\rho$ Red $)$ & {$[10]$} \\
MSAVI & $((\rho N I R-\rho$ Red $) /(\rho N I R+\rho$ Red $+L)) \times(1+L)$ & {$[11]$} \\
MSARVI & $\left(2 \rho N I R+1-\sqrt{((2 \rho N I R)+1)^{2}-\gamma(\rho N I R-\rho r b}\right) / 2$ & {$[12]$} \\
\hline
\end{tabular}

\subsection{Field Methods}

Canopy density measurement used hemispherical photography method. Hemispherical photography method usually used for canopy identification through upward or downward photo taking using wideangle camera [13]. This method gives information about gap fraction distribution that can be used for forest canopy properties, for example leaf area index, leaf angle distribution, and canopy openness [14].

Technically, canopy density data obtained by taking photo upwardly in constant height, 1 meter in every sample location. Photos were taken 5 times; 1 photo on the center of plot and others surrounding. According to Sentinel-2A pixel size $(10 \mathrm{~m})$, we build sample area $15 \times 15 \mathrm{~m}$ to anticipate the effect of surrounding objects and geometric error. Can-Eye software was used to obtain canopy density value. Total of 33 sample plots were completely obtained. Sample plots divided into 2 parts, 24 samples for modelling and 9 for accuracy assessment.

\subsection{Mangrove Canopy Density Modelling}

Mangrove canopy density modelling using regression analysis had a requirement that must be fulfilled for further analysis, a significant correlation. Pearson correlation was performed between canopy density data and vegetation index values. The next procedure was the analysis had to pass $\mathrm{F}$ and $\mathrm{T}$ test to determine the result of regression modelling whether could be used for modelling or not.

Regression analysis used four modelling methods that represent linear and non-linear regression. Nonlinear regression consists of quadratic, logarithmic, and exponential regression. The four models were identified using the equations as described on Table 2.

The accuracy value of each regression model was obtained from the calculation of standard error of estimation value. This error can be converted to minimum and maximum accuracy with $95 \%$ confidence level [15]. The maximum accuracy value is used as the accuracy comparison of each model. 
Table 2 Equation of vegetation index

\begin{tabular}{ll}
\hline Regression Model & Equation \\
\hline Simple linear & $\mathrm{Y}=\mathrm{a}+\mathrm{bX}$ \\
Quadratic & $\mathrm{Y}=\mathrm{a}+\mathrm{bX}+\mathrm{bX}^{2}$ \\
Logarithmic & $\mathrm{Y}=\mathrm{a}+\mathrm{b} \log \mathrm{X}$ \\
Exponential & $\mathrm{Y}=\mathrm{a} \mathrm{e}^{\mathrm{bx}}$ \\
& $\mathrm{e}=2.7183$ \\
\hline
\end{tabular}

\section{Results and Discussions}

Mangrove canopy density field data were divided into 2 parts, 24 data for modelling, and 9 data for accuracy assessment. First, the data was correlated using Pearson Product Moment. Normality of data was required in correlation analysis, thus we tested data normality using Kolmogorov Smirnov method. Mangrove canopy density data showed its normality with 0.082 significance value. The data was normal if the significance value is more than 0.05 . The normal distribution of data could be seen on QQ plot normal graphic (Fig. 2) which showed no outlier data.

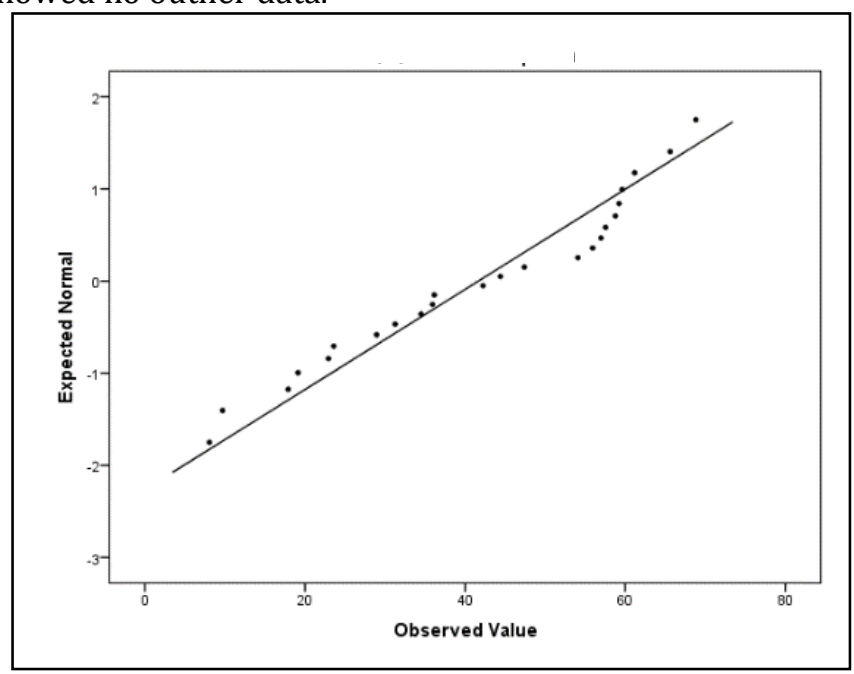

Fig. 2 Q-Q plot normal graph of canopy density data

Correlation and regression analysis were conducted with pixel value of vegetation index (NDVI, MSAVI, and MSARVI) as independent variable, and mangrove canopy density data as dependent variable. Regression methods compared in this study are simple linear, quadratic, logarithmic, and exponential regression. On Table 3 we can see correlation value on all regression models and vegetation indices have positive and strong correlation according to correlation class (0.6-0.799) [16], only NDVI using quadratic regression had very strong relationship, 0.8. MSARVI using logarithmic regression was the lowest model with correlation value 0.689 , but it was still had strong relationship. All correlations were significant, and it could be continued to regression analysis.

The next procedure of regression analysis was applying $\mathrm{F}$ test and $\mathrm{T}$ test. $\mathrm{F}$ test or model test was intended to find out the effect of independent variable, which the significance less than 0.05 means the independent variable can be used to predict the model. T test or partial test was intended to find out the effect of each independent variable individually toward dependent variable [17]. Regression analysis could be continued if it passed the tests. The tests results shown on the Table 4 . All of models were passed the $F$ test and $\mathrm{T}$ test, but the quadratic regressions in three vegetation indices were not. However, in this study the quadratic regression was concluded to compare it with the others and to be analyzed. 
Table 3 Coefficient of determination and $\mathrm{F}$ test results

\begin{tabular}{lllll}
\hline Vegetation index & Regression model & $\mathrm{r}$ & $\mathrm{R}^{2}$ & F test \\
\cline { 4 - 4 } & & & & Sig \\
\hline NDVI & Simple linear & 0.772 & 0.596 & 0.000 \\
& Quadratic & 0.800 & 0.640 & 0.000 \\
& Logarithmic & 0.728 & 0.530 & 0.000 \\
& Exponential & 0.799 & 0.639 & 0.000 \\
\hline MSAVI & Simple linear & 0.776 & 0.602 & 0.000 \\
& Quadratic & 0.777 & 0.604 & 0.000 \\
& Logarithmic & 0.736 & 0.542 & 0.000 \\
& Exponential & 0.762 & 0.581 & 0.000 \\
\hline MSARVI & Simple linear & 0.763 & 0.583 & 0.000 \\
& Quadratic & 0.776 & 0.602 & 0.000 \\
& Logarithmic & 0.689 & 0.474 & 0.000 \\
& Exponential & 0.766 & 0.587 & 0.000 \\
\hline
\end{tabular}

Table 4 Regression results

\begin{tabular}{|c|c|c|c|c|c|c|c|}
\hline \multirow{2}{*}{$\begin{array}{l}\text { Vegetation } \\
\text { index }\end{array}$} & \multirow[t]{2}{*}{ Regression model } & \multicolumn{6}{|c|}{ T test } \\
\hline & & $\beta_{0}$ & sig & $\beta_{1}$ & sig & $\beta_{2}$ & sig \\
\hline \multirow[t]{4}{*}{ NDVI } & Simple linear & 18.166 & 0.106 & 77.719 & 0.000 & & \\
\hline & Quadratic & 25.21 & 0.396 & -68.208 & 0.468 & 110.4 & 0.125 \\
\hline & Logarithmic & 54.826 & 0.000 & 44.051 & 0.000 & & \\
\hline & Exponential & 4.979 & 0.000 & 2.585 & 0.000 & & \\
\hline \multirow[t]{4}{*}{ MSAVI } & Simple linear & 2.673 & 0.713 & 108.63 & 0.000 & & \\
\hline & Quadratic & 6.785 & 0.659 & 79.405 & 0.418 & 43.87 & 0.759 \\
\hline & Logarithmic & 72.939 & 0.000 & 28.054 & 0.000 & & \\
\hline & Exponential & 10.647 & 0.000 & 3.426 & 0.000 & & \\
\hline \multirow[t]{4}{*}{ MSARVI } & Simple linear & 2.489 & 0.743 & 1281.91 & 0.000 & & \\
\hline & Quadratic & 13.186 & 0.324 & 268.93 & 0.798 & 19313 & 0.329 \\
\hline & Logarithmic & 123.83 & 0.000 & 22.86 & 0.000 & & \\
\hline & Exponential & 10.301 & 0.000 & 41.326 & 0.000 & & \\
\hline
\end{tabular}

Each regression analysis between vegetation index and mangrove canopy density data results equation or formula to extrapolate mangrove canopy density on the study area. The formula according to the intercept and coefficient that shown on the Table 5.

Table 5 Regression formula in this study

\begin{tabular}{llll}
\hline Regression & \multicolumn{2}{c}{ Vegetation index } \\
\cline { 2 - 4 } model & NDVI & MSAVI & MSARVI \\
\hline Simple linear & $77.72 \mathrm{x}-18.166$ & $108.63 \mathrm{x}+2.6734$ & $1281.9 \mathrm{x}+2.4888$ \\
Quadratic & $110.4 \mathrm{x}^{2}-68.208 \mathrm{x}+25.21$ & $43.872 \mathrm{x}^{2}+79.405 \mathrm{x}+6.7846$ & $19314.524 \mathrm{x}^{2}+268.94 \mathrm{x}+13.186$ \\
Logarithmic & $44.051 \ln (\mathrm{x})+54.826$ & $28.054 \ln (\mathrm{x})+72.939$ & $22.865 \ln (\mathrm{x})+123.83$ \\
Exponential & $4.9793 \mathrm{e}^{2.5848 \mathrm{x}}$ & $10.647 \mathrm{e}^{3.4264 \mathrm{x}}$ & $10.301 \mathrm{e}^{41.326 \mathrm{x}}$ \\
\hline
\end{tabular}


The model accuracy was obtained through upper range of accuracy standard error of estimation at confidence level $95 \%$. The maximum accuracy of each models shown on the Table 6. NDVI using simple linear regression was the best model with maximum accuracy $81.657 \%$.

Table 6 Accuracy of modelling

\begin{tabular}{lllll}
\hline & Simple linear & Quadratic & Logarithmic & Exponential \\
\hline NDVI & $81.657 \%$ & $80.837 \%$ & $80.675 \%$ & $80.715 \%$ \\
MSAVI & $77.295 \%$ & $76.937 \%$ & $78.795 \%$ & $73.947 \%$ \\
MSARVI & $78.717 \%$ & $62.782 \%$ & $79.185 \%$ & $76.576 \%$ \\
\hline
\end{tabular}

NDVI had consistent accuracy value on all of the regression type, more than $80 \%$. NDVI is standard vegetation index in common used, and several studies about mangrove canopy density using this image transformation to make the model [18]. The red and near infrared band as the input of NDVI transformation have the ability to explain the variation of biophysical vegetation condition strongly [15]. Kamal [5] reported NDVI was suitable to map various mangrove features such as vegetation cover type, vegetation formation/ community, double tree crown/ larger gaps, single tree crown, canopy gaps, foliage clumping, and single shrub crown in various pixel size with maximum $10 \mathrm{~m}$.

MSAVI had the lowest accuracy if it seen in overall on the regression models. MSAVI transformation used soil adjusted factor to reduce the effect of soil background. Soil line which used in the algorithm was 1.06, according to Qi et al [12]. It would be better if soil line was measured empirically, moreover the study area is mangrove forest that lies on the wetland with mud soils, different to inland soils.

MSARVI had various accuracy value on all regression models. MSARVI could reduce the effect of soil background and atmosphere at once [6]. However, it could reduce atmospheric effect, the coastal condition had evaporation and evapotranspiration excessively, and it had the possibility to disturb the accuracy of this model [17]. However, the mangrove canopy density models using MSARVI were better than MSAVI which only considering soil background effect.

Simple linear regression showed the best accuracy value, with the accuracy value of NDVI was 81.657 $\%$, and consistent on MSAVI and MSARVI, which are $77.295 \%$ and $78.717 \%$ respectively. Heiskanen [19] on his research recommended using the linear regression model to estimate biomass and LAI. Several studies on canopy densities have been widely used simple linear regression and showed good accuracy values.

The quadratic regression model showed an inconsistent accuracy when it applied on NDVI (80.837\%), MSAVI (76.937\%), and MSARVI (62.782\%). This condition was influenced by the polynomial characteristic which becomes the basis of the equation, and by the distribution of samples used as sample model and validation samples. The polynomial characteristic of quadratic regression caused the shape of the curve becomes parabolic curve [20]. This condition can be seen on the quadratic regression figure of NDVI which shows the lowest NDVI value yields high canopy density value, then the canopy density value is slightly decreasing with the increasing of NDVI value, and then the canopy density value rises again. This condition is not the same as the theoretical of the NDVI which the higher value of the NDVI, the more represents vegetation features [21]. Distribution of samples greatly affected regression results, where non-linear regression will follow the form of sample plots, especially in quadratic regression type, so if the accuracy assessment use different samples, it will greatly affect its accuracy.

The exponential regression used the principle of curve formation using the $b$ value to set the degree becomes positive or negative curve, whereas $a$ as intercept [20]. The exponential curve shows an increasingly saturated curve at a certain point. The modelling results using exponential regression showed a positive curve. It showed the saturation of pixel values for the higher canopy density, similar with the model using quadratic method.

Logarithmic regression curve on all vegetation indices were saturated in $\mathrm{Y}$ variable. Accuracy assessment results showed logarithmic model had the most consistent accuracy value than other regression models. Logarithmic regression model had accuracy value of $80.675 \%$ (NDVI), $78.795 \%$ (MSAVI), and $78.185 \%$ (MSARVI). It showed the saturation of canopy density values on the higher vegetation index values, so that no canopy density values reach more than $100 \%$. This condition was different from the curve of the quadratic and exponential regression model which allowed the canopy density value to be more than $100 \%$. The lack of sample data at high density (>60\%) caused saturation to be occurred earlier, so the estimation of canopy density became underestimate.

The result of the comparison of the four types of regression showed that simple linear and logarithmic were good regression types used for modelling mangrove canopy density estimation in the study area. 
Basically, the three types of non-linear regression (quadratic, logarithmic, and exponential) had a straightlined form of equation, but differed in expressing it [20]. The important thing to consider in modelling using non-linear regression was the distribution of the sample was really normal and in great quantities, because non-linear regression curve will be easily affected especially with the small number of samples. Selection of regression type could be determined beforehand by performing scatterplot analysis on variables $\mathrm{x}$ and $y$. It was clear that simple linear regression takes into account the linearity of the relationship between the two variables. On the other hand, fitting curves on non-linear regressions were performed by transforming values of variables, logging $\mathrm{x}$ on logarithmic regression, logging $\mathrm{y}$ alone on exponential regression, and quadratic straightened by replacing $\mathrm{x}$ by its reciprocal [20]. Scatterplot analysis was very important to know how the relationship between variables used.

The mangrove canopy density modelling was derived from the relationship between the vegetation index value parameter on the Sentinel-2A image and the field measured density samples. The vegetation index used was NDVI, MSAVI, and MSARVI with linear, quadratic, logarithmic, and exponential regression methods. Each regression result between vegetation index (dependent variable) and sample data of mangrove canopy density in the field (independent variable) give certain equation or formula to extrapolate mangrove canopy density in all study area. A high correlation between vegetation index values and field data illustrates a well-used model used to estimate the density of the canopy in all areas of the study. The level of correlation can be described from the value of coefficient of determination of the regression results.
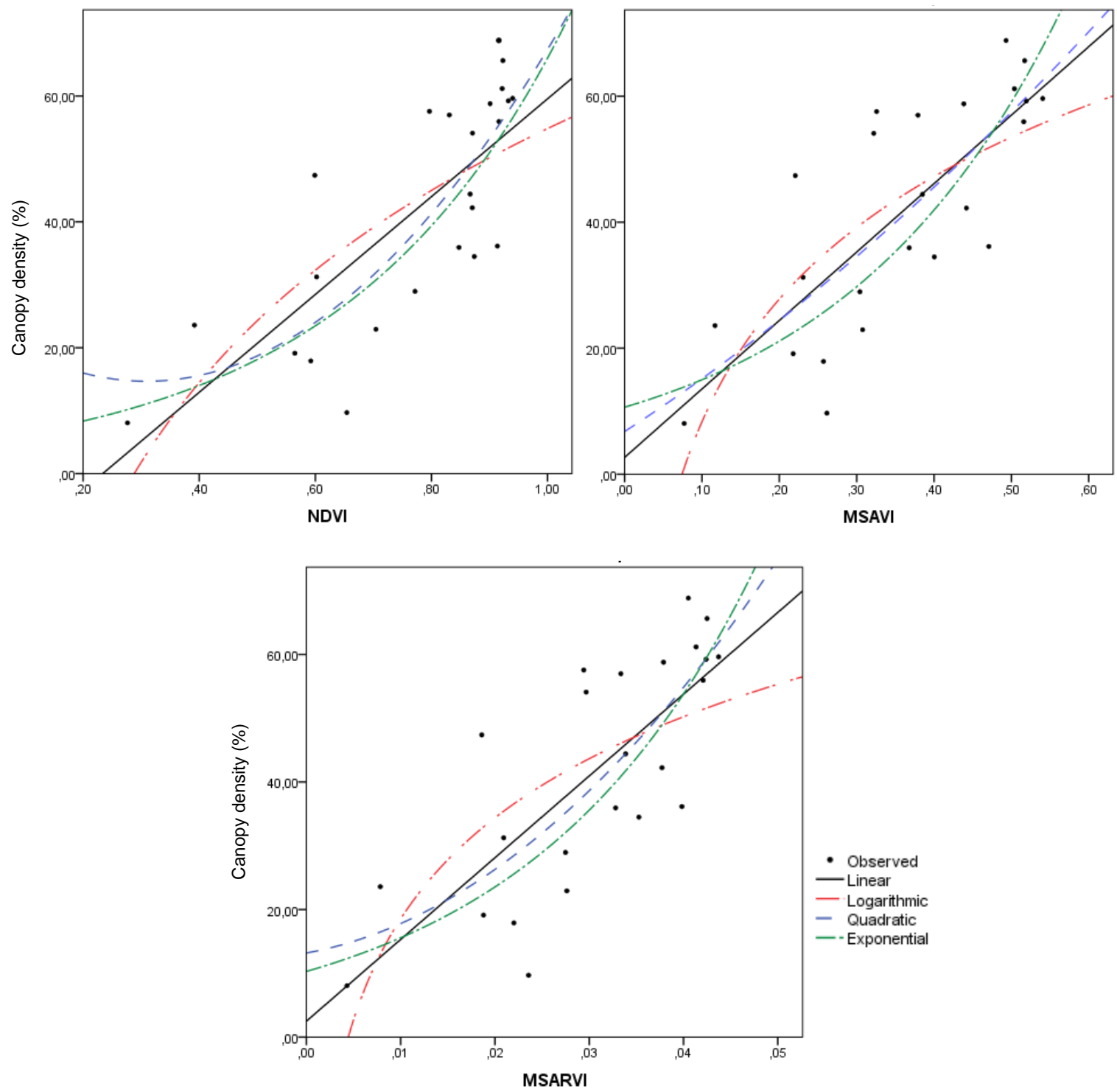

Fig. 3 Regression graph between vegetation index and field data 
Comparison of accuracy between regression models with vegetation index showed linear regression in NDVI has the best accuracy value that is $81.657 \%$. This condition makes mangrove canopy density mapping in the study area using linear regression method between NDVI data with canopy density data. Mapping of mangrove canopy density using regression method with best accuracy value is considered to be able to present spatial distribution of mangrove canopy density resembling the actual condition in the field.

Figure 4 showed the spatial distribution of mangrove canopy density at Jor and Kecebing Bay. In general, canopy density condition in both locations had a similar pattern on the map of linear regression analysis between NDVI data and canopy density data. The value of mangrove canopy density on the best model showed in the range $-46.3254-57.9048 \%$. The negative values mean they were not the vegetation objects, and they were ignored. They were appeared because there were some mixed pixels between vegetation and other objects (water and soil). It was necessary to classify the mangrove forest using classification methods such as multispectral classification, but it was not performed in this study. The canopy density on the coastline area was higher than the area toward the land. Further from the coastline, the mangrove canopy density is lower. In fact, the distribution of canopy density might be affected by several factors, such as structure, composition, diversity, and distribution pattern [22], but in this research those factors were not considered.

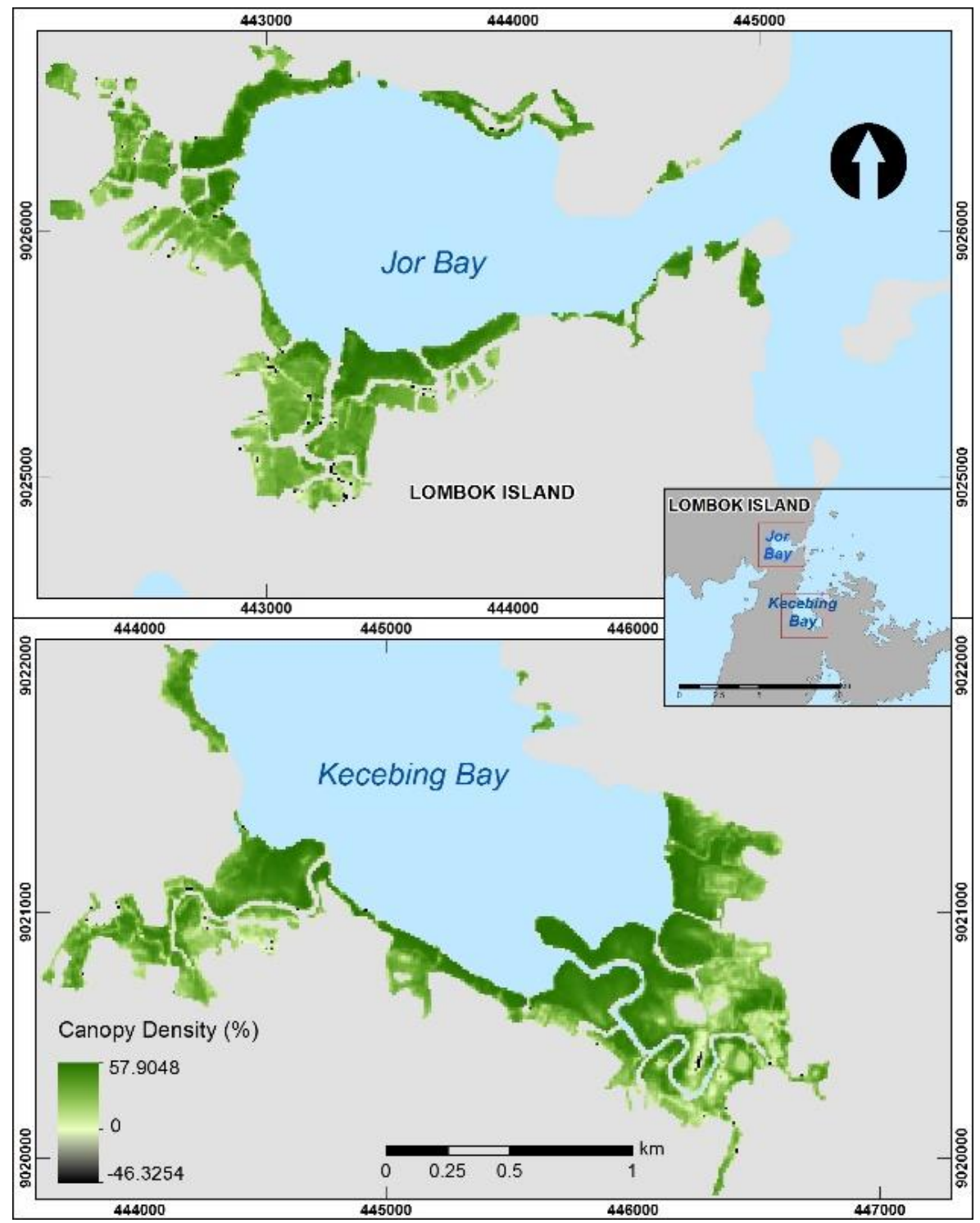

Fig. 4 Spatial distribution of mangrove canopy density with linear regression on NDVI value and field data

On Figure 4, the lowest density of the mangrove canopy is concentrated in the river flow across the mangrove forest. If it viewed as a whole, mangrove canopy density conditions in the study area varied considerably. The increasing trend of canopy density in the area near the shoreline is very much in line 
with the actual conditions in the field. The existence of fishpond also affected the mangrove condition. We could see the agro fishery activities was very dominant in the study area. Some former ponds are starting covered by new mangrove communities.

Figure 5 showed the spatial distribution of the canopy density as the result of modelling using quadratic regression method between MSARVI data and mangrove canopy density data. The modelling accuracy reached $62.782 \%$. The canopy density value ranges between 12.249 to $67.9464 \%$. The canopy density distribution in this model is different from the mangrove canopy density condition in the model resulted by the best regression method.

The result of modelling using quadratic regression between MSARVI data and canopy density data showed the whole area almost had identical canopy density. High canopy density was not presented on all coastline areas, there were also some sides on coastline areas that had low canopy density. From this model result, mangrove canopy density condition was still less varied, inversely with the result of mangrove canopy density modelling using linear regression method between NDVI data and canopy density data.

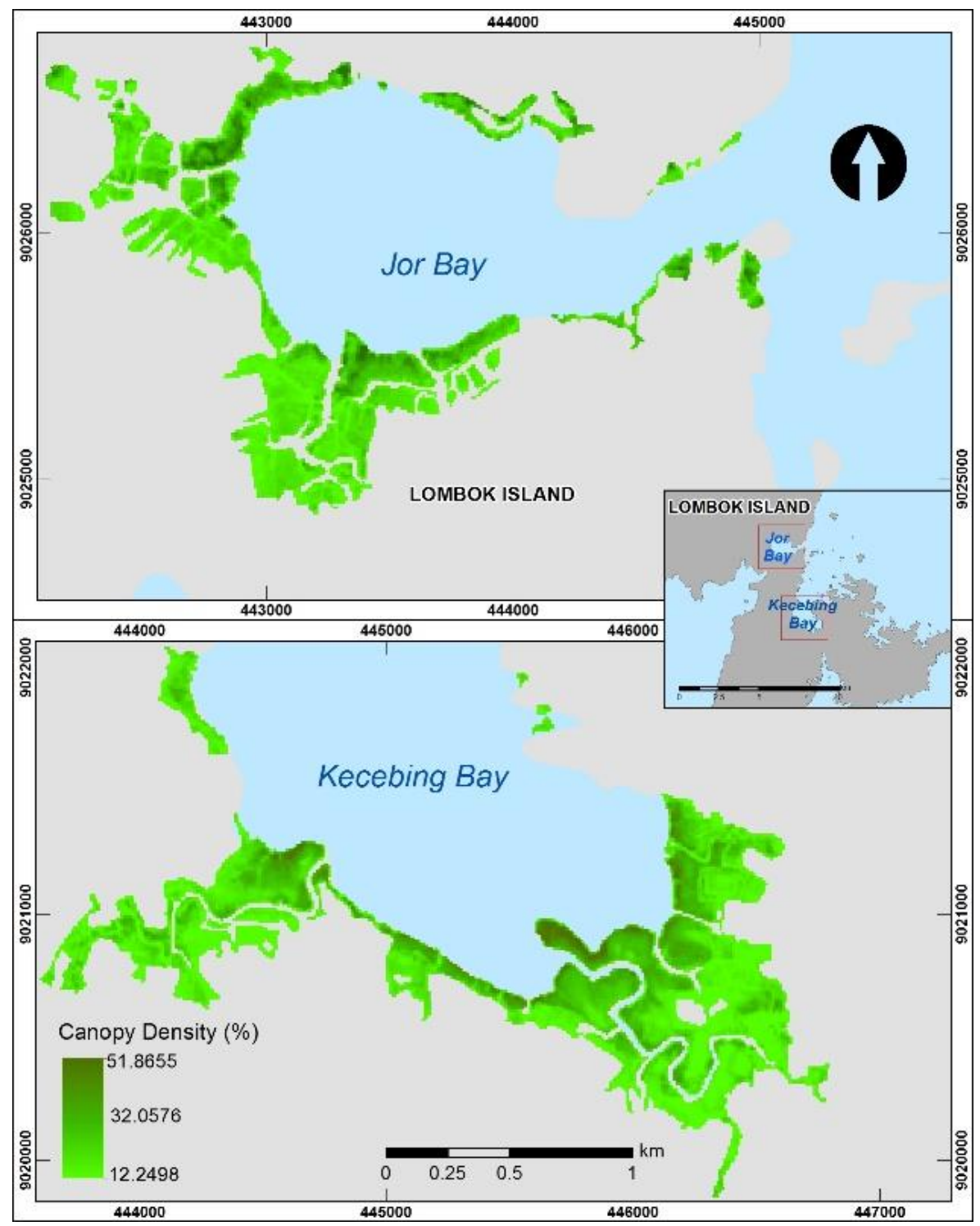

Fig. 5 Spatial distribution of mangrove canopy density with quadratic regression on MSARVI value and field data 


\section{Conclusions}

NDVI is the best vegetation index in mangrove canopy density modelling at Jor Bay and Kecebing Bay, East Lombok. According to this study, NDVI had consistent accuracy in overall regression model with the accuracy value above $80 \%$. Highest accuracy value is $81.657 \%$ resulted from linear regression between NDVI value and field data. Lowest accuracy value is $62.782 \%$, resulted from quadratic regression analysis between MSARVI and canopy density data from field measurement. The result of the comparison of four regression types showed that simple linear and logarithmic were good regression methods used for modelling mangrove canopy density estimation in the study area. Selection of regression type could be determined beforehand by performing scatterplot analysis on variables $\mathrm{x}$ and $\mathrm{y}$. It was clear that simple linear regression takes into account the linearity of the relationship between the two variables. If it had a curved relationship, it could be performed non-linear regression, but the number and distribution of data is very required.

Acknowledgments This research was conducted by two members of "Mangrove Team" of Field Work III Cartography and Remote Sensing, Department of Geography Information Science, Faculty of Geography, Universitas Gadjah Mada. The team members are Muchsin Nur Wachid, Akbar Muammar Syarif, Deha Agus Umarhadi, Raden Pranantya Hapsara, Restu Dwi Cahyo, Dyah Puteri Ramadhanningrum, Ayuni Nur Fitriani, Gina Nur Wahyu, and supervised by Wirastuti Widyatmanti, Ph.D. The data was measured by team and supported by all of Cartography and Remote Sensing students and lecturers.

\section{References}

1. Khambete, A., Jagdish, S.: Role of mangroves on domestic wastewater discharge: Case study at Jamnagar coastal region. pp. 359-362. IEEE, India In. (2010).

2. Hogarth, P.: The biology of mangroves and seagrasses. pp. 2 Oxford University Press, Oxford University Press (2007).

3. Ishtiaque, A., Myint, S.W., Wang, C.: Examining the ecosystem health and sustainability of the world's largest mangrove forest using multi-temporal MODIS products. Science of the Total Environment. 569-570:1241-1254 (2016).

4. Noor, Y.R., Khazali, M., Suryadiputra, I.N.: Panduan pengenalan mangrove di indonesia [A guide of mangrove introduction in Indonesia]. $2^{\text {nd }}$ edition, pp. 21. PKA/WI-IP:Bogor (2006). [in Bahasa Indonesia].

5. Kamal, M., Phinn, S., Johansen, K.: Characterizing the spatial structure of mangrove features for optimizing image-based mangrove mapping. Remote Sens. 6:984-1006 (2014).

6. Danoedoro, P.: Pengantar penginderaan jauh digital [Introduction to digital remote sensing], pp. 206-256. CV Andi Offset, Yogyakarta (2012).

7. Jensen, J.R.: Remote sensing of the environment: An earth resource perspective. pp. 384. Pearson Prentice Hall, New Jersey (2007).

8. Myeong, S., Nowak, D.J., Duggin, M.J.: A temporal analysis of urban forest carbon storage using remote sensing. Remote Sensing of Environment 101:277-282 (2006).

9. Myneni, R.B., Nemani, R.R., Running, S.W.: Estimation of global leaf area index and absorbed par using radiative transfer models. IEEE Transaction on Geoscience and Remote Sensing. 35(6):1380-1393 (1997).

10. Rouse, J.W., Hass, R.H., Schell, J.A., Deering, D.W.: Monitoring vegetation systems in the great plains with ERTS. Proc. Third Earth Resources Technology Satellite-1 Symposium SP-351, 3010-3017.

11. Qi, J., Chehbouni, A., Huete, A.R., Kerr, Y.H., Sorooshian, S.: A Modified soil adjusted vegetation index. Remote Sens. Environ., 48: 119-126 (1994). 
12. Huete, A.R., Hua, G., Chehbouni, A., van Leeuwen, W. J. D.: Normalization of multidirectional red and NIR reflectance with the SAVI. Remote Sens. Environ., 41: 143-154 (1992).

13. Jonckheere, I., Fleck, S., Nackaerts, K., Muys, B., Coppin, P., Weiss, M., Baret, F. Review of methods for in situ leaf area index determination: Part I. theories, sensors and hemispherical photography. Agricultural and Forest Meteorology 2004; 121 (1-2): 19-35 (2004). doi: 10.1016/j.agrformet.2003. 08.027

14. Chianucci, F., and Cutini, A. Digital hemispherical photography for estimating forest canopy properties: current controversies and opportunities. iForest 5: 290-295 (2012).

15. Wicaksono, P., Danoedoro, P., Hartono, Nehren, U., Ribbe, L. Preliminary work of mangrove ecosystem carbon stock mapping in small island using remote sensing: Above and below ground carbon stock mapping on medium resolution satellite image. SPIE Conference Proceedings 8 1741 (2011).

16. Sugiyono.: Statistika untuk Penelitian [Statistics for Research]. pp. 231. Penerbit Alfabeta, Bandung (2014). [In Bahasa Indonesia].

17. Ashaari, F.: Perbandingan Akurasi Estimasi Kerapatan Kanopi Pohon Menggunakan Saluran Tunggal, Indeks Vegetasi dan Model Forest Canopy Density Berbasis Citra Landsat-8 (Lokasi Sebagian Hutan Rawa Gambut Provinsi Riau). [Comparison of accuracy for estimating tree canopy density use single band, vegetation indices, and forest canopy density model based on Ladnsat-9 Imagery: Location a part peat swamp forset in Riau Priovince] pp. 46-79. [Thesis]. Faculty of Geography, Universitas Gadjah Mada (2016). [in Bahasa Indonesia].

18. Yuvaraj, E., Dharanirajan, K., Saravanan., Karpoorasundarapandian, N.: Evaluation of vegetation density of the mangrove forest in south Andaman island using remote sensing and GIS techniques. International Research Journal of Environment Sciences 3(8):19-25 (2014).

19. Heiskanen, J.: Estimating above ground tree biomass and leaf area index in a mountain birch forest using ASTER satellite data. International Journal of Remote Sensing 27(6):1135-1158 (2006).

20. Shaw, G., Wheeler, D.: Statistical techniques in geographical analysis. pp. 199-225. Norwich, John Willey and Sons Ltd. (1985).

21. Bhandari, A.K., Kumar, A., Singh, G.K.: Feature extraction using normalized difference vegetation index (NDVI): A Case Study of Jabalpur City Procedia Technology 6:612-621 (2012).

22. Sukarna, R.M., Syahid, Y.: FCD Application of Landsat for Monitoring Mangrove in Central Kalimantan. Indonesian Journal of Geography 47(2):160-170 (2015). 